\title{
Evidence of improving antiretroviral therapy treatment delays: an analysis of eight years of programmatic outcomes in Blantyre, Malawi
}

Derek J Sloan ${ }^{1,2}$, Joep J van Oosterhout ${ }^{3}$, Ken Malisita ${ }^{3}$, Eddie M Phiri ${ }^{3}$, David G Lalloo ${ }^{4}$, Bernadette O'Hare ${ }^{3}$ and Peter MacPherson ${ }^{1,4,5^{*}}$

\begin{abstract}
Background: Impressive achievements have been made towards achieving universal coverage of antiretroviral therapy (ART) in sub-Saharan Africa. However, the effects of rapid ART scale-up on delays between HIV diagnosis and treatment initiation have not been well described.

Methods: A retrospective cohort study covering eight years of ART initiators (2004-2011) was conducted at Queen Elizabeth Central Hospital (QECH) in Blantyre, Malawi. The time between most recent positive HIV test and ART initiation was calculated and temporal trends in delay to initiation were described. Factors associated with time to initiation were investigated using multivariate regression analysis.

Results: From 2004-2011, there were 15,949 ART initiations at QECH (56\% female; 8\% children [0-10 years] and 5\% adolescents [10-20 years]). Male initiators were likely to have more advanced HIV infection at initiation than female initiators (70\% vs. $64 \%$ in WHO stage 3 or 4). Over the eight years studied, there were declines in treatment delay, with 2011 having the shortest delay at 36.5 days. On multivariate analysis CD4 count $<50$ cells/ul (adjusted geometric mean ratio [aGMR]: aGMR: 0.53, bias-corrected accelerated [BCA] 95\% Cl: 0.42-0.68) was associated with shorter ART treatment delay. Women (aGMR: 1.12, BCA 95\% Cl: 1.03-1.22) and patients diagnosed with HIV at another facility outside QECH (aGMR: 1.61, BCA 95\% Cl: 1.47-1.77) had significantly longer treatment delay.

Conclusions: Continued improvements in treatment delays provide evidence that universal access to ART can be achieved using the public health approach adopted by Malawi However, the longer delays for women and patients diagnosed at outlying sites emphasises the need for targeted interventions to support equitable access for these groups.
\end{abstract}

Keywords: HIV, Antiretroviral therapy, Linkage to care, HIV testing and counselling, Africa, Programmatic research

\section{Background}

Since 2003, there have been tremendous global achievements in scaling up delivery of antiretroviral therapy (ART) for people infected with HIV, with over 6.6 million people now receiving treatment [1]. The most impressive gains have been seen in sub-Saharan Africa. In 2009, 3.9 million people in the region were taking ART but by the

\footnotetext{
* Correspondence: p.macpherson@liverpool.ac.uk

'Malawi-Liverpool-Wellcome Trust and Liverpool School of Tropical Medicine, Chichiri 3, PO 30096, Blantyre, Malawi

${ }^{4}$ Faculty of Infectious and Tropical Diseases, Department of Clinical Sciences, Keppel Street, London, UK

Full list of author information is available at the end of the article
}

end of 2011, more than 5.1 million people had been initiated onto ART, a $27 \%$ increase [2].

Malawi, one of the poorest countries in the world, has pioneered the public health approach to ART delivery $[3,4]$. The public health approach involves decentralisation of ART delivery to primary health care clinics, task-shifting from clinicians to nurses and counsellors, and a reporting system based on collection of facility-level aggregate statistics that allow clear analysis of trends in HIV testing data, uptake of ART and outcomes of ART initiators [5]. By mid-2011, more than 400,000 HIV-infected Malawians had initiated ART through the National Programme [6].

\section{Biomed Central}


Although the rapid scaling up of ART programmes have been impressive in their speed, impact upon population mortality and on reducing HIV incidence [2], there are increasing concerns about the effect that an ever-expanding number of patients requiring life-long clinical management will have on staff workload and ART clinic sustainability. Moreover, a recent systematic review has highlighted the high rate of attrition in the pre-ART period [7], with long delays and failures to complete eligibility assessments (CD4 counts and WHO clinical staging assessments) major contributors to suboptimal retention before initiation [8]. Alternatively, as ART guidelines are expanded to include individuals with higher CD4 counts, treatment delays may be shortened.

This study examined changing patterns in length of time between diagnosis of HIV infection and initiation of antiretroviral therapy ("ART treatment delay") at the largest single public health facility providing ART in Malawi over eight years. The objectives were to describe temporal trends in ART treatment delay and investigate factors associated with increased risk of delay since ART became available free-of-charge at the clinic.

\section{Methods}

\section{Study design}

A retrospective cohort study.

\section{Study site and population}

Queen Elizabeth Central Hospital (QECH) is the largest public health facility in Malawi and is a referral centre for patients in the Southern Region of the country. The ART clinic at QECH was established as a fee-paying clinic in 2000 and since 2004, ART has been provided free-of-charge according to the National Ministry of Health scale-up programme. The QECH ART clinic profile and outcomes of patients initiating ART have been described in detail previously [9].

Clinical and socio-demographic details of all ART initiators have been prospectively entered into the clinic's electronic data management system [10] since 2008 . Records of ART initiators before this date have been retrospectively captured and validated.

From 2003 until 2006, Malawi National ART eligibility criteria for adults ( $\geq 15$ years) were presence of a WHO stage 3 or 4 defining illness, or a CD 4 count of $<200$ cells/ $\mu \mathrm{l}$, or a total lymphocyte count (TLC) in an individual in WHO stage 2 of $<1200$ cells $/ \mu$ (Figure 1 ). The CD4 count threshold was revised upwards to a cut-off of $<250$ cells $/ \mu$ l in 2006 and to $<350$ cells/ $\mu$ lin September 2011.

For children less than 15 years old ART initiation guidelines in Malawi have evolved in line with the publication of new evidence over the years. From, 2003 to 2006, children younger than 18 months old who were eligible for ART if their CD4 percentage was $<25 \%$ or

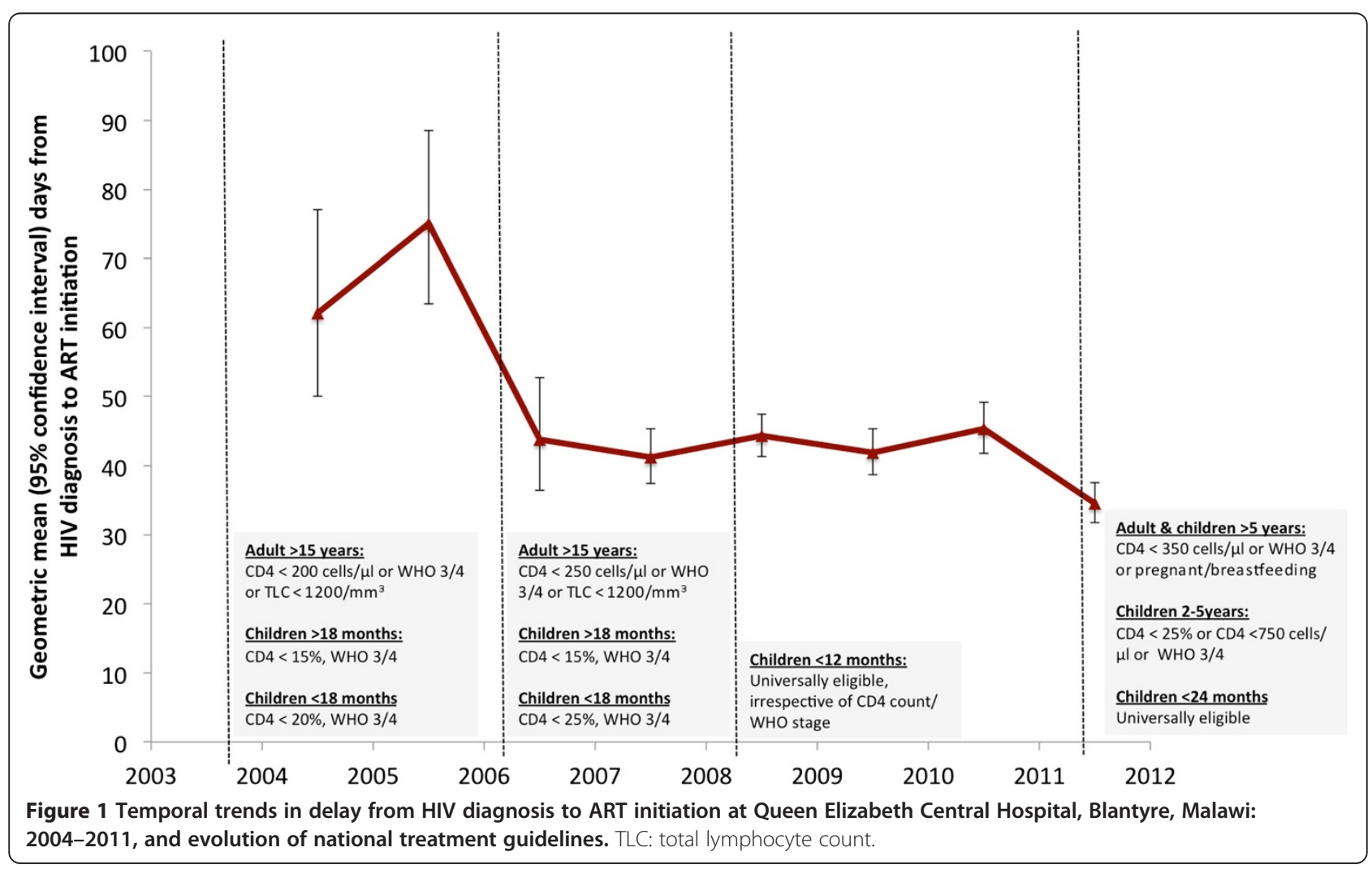


they were in WHO paediatric stage 3 or 4 . Children aged older than 18 months if their CD4 percentage was $<15 \%$. As new evidence became available the guidelines were updated and the thresholds for starting ART in asymptomatic children lowered. In 2008 national guidelines were updated to recommend that all children aged younger than 12 months with a confirmed or presumed diagnosis of HIV were universally eligible for ART, regardless of immune status. This was extended to all children younger than 24 months in September 2011.

In this study, we extracted data from the ART clinic database for the period from January 2004 to December 2011 when ART was available free-of-charge. Individuals who initiated ART between 2004 and 2011 (regardless of date of HIV diagnosis) were eligible for inclusion.

\section{Defining ART treatment delay}

Cohort entry was defined as the date of most recent positive HIV test recorded in the ART clinic database. Cohort exit was defined as the date of ART initiation. Where either the date of last positive HIV test or the date of ART initiation was missing from the database, the patient was not included in the analysis.

\section{Statistical methods}

Statistical analysis was conducted using Stata/IC 11.2 (College Station, Texas, USA). Baseline characteristics of ART initiators were stratified by sex and compared using Pearson's chi-square tests for categorical variables and Student's $t$ test for continuous variables. Children were defined as being between 0 and 10 years at ART initiation and adolescents between 10 and 20 years at initiation.

Number of days between last positive HIV test and initiation of ART showed a highly skewed distribution and results were therefore transformed to $\log _{e}$ before analysis. Mean number of days to ART initiation was compared between groups and by cohort year using linear regression with back-transformation of regression coefficients to obtain geometric mean ratios (GMRs). As some results remained skewed after $\log _{\mathrm{e}}$ transformation, analyses were bootstrapped with 10,000 repetitions to estimate bias-corrected accelerated confidence intervals. Variables considered as a priori confounders (age, sex, CD4 count, year of initiation), and variables that were significant at the $\mathrm{p}<0.10$ level on univariate analysis, were included in the adjusted multivariate model.

\section{Ethical considerations}

The College of Medicine of Malawi Research Ethics Committee granted ethical approval for this study. As this was a retrospective study analysing routinely collected data, individual consent was not sought. All patient identifiers were removed prior to analysis.

\section{Results}

\section{Baseline characteristics}

Between January 2004 and December 2011, there were 15,949 ART initiations at the QECH ART Clinic, with more females $(8,988,56.4 \%)$ than males $(6,961,43.6 \%)$ starting treatment. Characteristics of the ART initiators, stratified by sex, are shown in Table 1 . Male initiators were older than female initiators (median: 34 years, interquartile range [IQR]: $27-42$ vs. 31 years, IQR: $25-38$; $\mathrm{p}<0.001$ ) and were more likely to have to have advanced HIV infection at initiation: 4,876/6,961 (69.9\%) of male

Table 1 Baseline characteristics of ART initiators at Queen Elizabeth Central Hospital between 2004 and 2011

\begin{tabular}{lccccc}
\hline Variable & Female & $\%$ & Male & $\%$ & P-value \\
\hline Total & 8,988 & & 6,961 & & \\
$\begin{array}{l}\text { Median age at initiation } \\
\text { (years); IQR }\end{array}$ & 31 & $25-38$ & 34 & $27-42$ & $<0.001$ \\
\hline
\end{tabular}

(years); IQR

Age group at initiation

\begin{tabular}{lccccc}
\hline 0-5 years & 475 & 5.3 & 537 & 7.8 & $<0.001$ \\
\hline 5-15 years & 583 & 6.5 & 521 & 7.5 & \\
\hline 15-25 years & 1,042 & 11.7 & 335 & 4.9 & \\
\hline 25-35 years & 3,715 & 41.6 & 2,033 & 29.4 & \\
\hline 35-45 years & 2,077 & 23.3 & 2,091 & 30.3 & \\
\hline$\geq 45$ years & 1,040 & 11.6 & 1,387 & 20.1 & \\
\hline Site of HIV test & & & & & 0.860 \\
\hline QECH & 3,023 & 33.6 & 2,361 & 33.9 & \\
\hline Outside QECH & 4,140 & 46.1 & 3,176 & 45.6 & \\
\hline Unknown & 1,825 & 20.3 & 1,424 & 20.5 & \\
\hline WHO stage at initiation & & & & & $<0.001$ \\
\hline Stage 1 or 2 & 3,264 & 36.3 & 2,094 & 30.1 & \\
\hline Stage 3 or 4 & 5,724 & 63.7 & 4,867 & 69.9 & \\
\hline
\end{tabular}

CD4 count $(\text { cells/ } / \mu)^{*}$

\begin{tabular}{lccccc}
\hline$\geq 350$ & 167 & 3.8 & 103 & 3.1 & $<0.001$ \\
\hline $250-350$ & 1,013 & 22.9 & 755 & 22.7 & \\
\hline $50-250$ & 2,719 & 61.4 & 1,930 & 58.1 & \\
\hline$<50$ & 528 & 11.9 & 533 & 16.1 &
\end{tabular}

Year of ART initiation

\begin{tabular}{lccccc}
\hline 2004-2005 & 562 & 6.3 & 404 & 5.8 & $<0.001$ \\
\hline $2005-2006$ & 1,208 & 13.4 & 801 & 11.5 & \\
\hline $2006-2007$ & 1,250 & 13.9 & 887 & 12.7 & \\
\hline $2007-2008$ & 1,253 & 13.9 & 1,010 & 14.5 & \\
\hline $2008-2009$ & 1,249 & 13.9 & 964 & 13.9 & \\
\hline $2009-2010$ & 1,134 & 12.6 & 1,024 & 14.7 & \\
\hline 2010-2011 & 1,154 & 12.8 & 1,002 & 14.4 & \\
\hline 2011-2012 & 1,178 & 13.1 & 866 & 12.4 & \\
\hline $\begin{array}{l}\text { Median time (days) } \\
\text { between last positive }\end{array}$ & 36 & $14-120$ & 33 & $12-94$ & \\
HIV test and initiation of & & & & & \\
ART; IQR & & & & & \\
\hline *CD4 count measured in 4,427 women and 3,321 men. Denominator for this
\end{tabular}

*CD4 count measured in 4,427 women and 3,321 men. Denominator for this variable is number of men and women who had CD4 count measured. 
initiators were in stage 3 or 4 compared to 5,724/8,988 $(63.7 \%)$ of female initiators $(\mathrm{p}<0.001)$; and a greater proportion of male initiators $(533 / 3,321,16.1 \%)$ had a CD4 count of $<50$ cells $/ \mu \mathrm{l}$ at initiation compared to female initiators $(528 / 4,427,11.9 \%)$.

There were no differences in the site of the last positive HIV test, with a similar proportion of males $(3,176 /$ $6961,45.6 \%)$ and females $(4,140 / 8,988,46.1 \%)$ testing at sites outside of QECH $(\mathrm{p}=0.860)$.

\section{Child and adolescent ART initiators}

Similar proportions of child (0-10 years) ART initiators were male $(884 / 1,694,52.2 \%)$ and female $(810 / 1,694$, $47.8 \%)$. However, adolescent (10-20 years) initiators were significantly less likely to be male than female (342/856 [40.0\%] vs. 514/856 [60.0\%]). Adolescents had the highest proportion of ART initiators who were in WHO stage 3 or $4(614 / 586,71.7 \%)$ compared to children $(1,089 / 1,694,64.3 \%)$ and adults older than 20 years $(8,888 /$ 13,399, 66.3\%). Additionally, adolescents (58/380, 15.3\%) were most likely to initiate ART with a CD4 count of $<50$ cells/ $\mu$ l compared to children $(33 / 666,5.0 \%)$ and adults $(970 / 6,702,14.5 \%)$.

\section{Temporal trends in delay from last positive HIV test to initiation of ART}

In total, 9,511/15,949 (59.6\%) ART initiators had complete data for date of ART initiation and date of most recent positive HIV test with the remaining 40.4\% of individuals having missing data for either date of ART initiation, HTC or both. There were no differences between individuals with missing and non-missing outcome data in terms of age group, sex and CD4 count strata. However, individuals initiating ART at QECH were less likely to have missing date of HIV diagnosis than individuals initiating ART at another clinical site. The overall median treatment delay in the group with complete data for delay in ART initiation was 35 days (IQR: 13-107).

Men (33 days, IQR: 12-94) had a shorter median ART treatment delay compared to women (36 days, IQR: 14120; $\mathrm{p}=0.001)$. There were slightly longer median time to initiation for children (40 days, IQR: 14-114) and adolescents (39 days, IQR: 13-127) compared to adults (34 days, IQR: 13-105); $\mathrm{p}<0.001$.

In the years immediately following introduction of free ART in the clinic, there was a trend towards increasing ART treatment delay (Figure 1), with a peak in 2005 (geometric mean: 67.3 days, 95\% CI: 58.9 - 76.8). However between 2005 and 2007, there was a rapid decline in ART treatment delay to a lowest geometric mean of 43.3 days (95\% CI: 39.7 - 47.3). Between 2007 and 2010, there was a slow upwards trend in treatment delay, but followed by a sharp decline in 2011, where the geometric mean number of days of ART treatment delay was 36.5 days (95\% CI: 33.7-39.6).

\section{Clinical and temporal associations with time from last positive HIV test to initiation of ART}

On univariate analysis (Table 2), female initiators experienced longer treatment delays (geometric mean ratio [GMR]: 1.13, bias corrected accelerated [BCA] 95\% CI: 1.06-1.21) compared to male initiators. Younger children in the $0-5$ years age group had shorter treatment delays (GMR: 0.87, BCA 95\% CI: 0.75-0.99), compared to adults in the 25-35 years age group, whereas older children and adolescents in the 5-15 year age group were had a longer delays (GMR: 1.16, BCA 95\% CI: 0.99-1.37).

ART initiators whose last positive test for HIV was at a clinical facility outside of QECH (any other HIV care facility) were more likely to experience delay (GMR: 1.65, BCA 95\% CI: 1.54-1.77). Whereas advanced WHO clinical stage (stage 3 or 4) was not associated with delay (GMR: 1.01, BCA 95\% CI: 0.95-1.08), individuals with an initiation CD4 count of $<50$ cells/ $\mu$ l (GMR: 0.50, BCA 95\% CI: 0.40-0.63) and 50-200 cells/ $\mu$ (GMR: 0.76, BCA: 0.61-0.95) had significantly lower treatment delay than individuals with a CD4 count of $\geq 350$ cells $/ \mu$ l.

When examined by year, a trend of significantly declining ART treatment delay compared to the year with the longest time from HIV-positive test to ART initiation (2005) was seen (test for trend $\mathrm{p}<0.001$ ). The lowest risk of delay was in 2011 (GMR: 0.54, BCA 95\% CI: 0.47-0.63).

On multivariate adjusted analysis, women remained more likely to experience a longer ART treatment delay than men (adjusted GMR [aGMR]: 1.12, BCA 95\% CI: 1.03-1.22), however there was no significant association between age group at initiation and delay $(\mathrm{p}=0.526)$. Individuals whose last positive HIV test was outside of QECH had a longer delay to ART initiation (aGMR: 1.61, BCA 95\% CI: 1.47-1.77). Lower CD4 count remained significantly associated with shorter delay to initiation, with individuals in the $<50$ cells $/ \mu$ group (aGMR: 0.53, BCA 95\% CI: 0.42-0.68) and the 50-200 cells/ $\mu$ l group (aGMR: 0.77, BCA 95\% CI: 0.62-0.98) compared to those in the $\geq 350$ group. There remained a non-significant trend towards shorter delay over the years studies (test for trend: $\mathrm{p}=0.089$ ).

\section{Discussion}

The main finding from the study was the evidence of sustained improvements in ART treatment delay from most recent positive HIV test to initiation of ART over eight years of rapid programmatic scale-up, a period during which nearly 16,000 individuals initiated treatment. The most recent year that was analysed (2011) had the shortest mean treatment delay, suggesting that the public health approach to ART delivery [3] that is 
Table 2 Univariate and multivariate associations with time from last positive HIV test and initiation of ART

\begin{tabular}{|c|c|c|c|c|c|}
\hline Variable & $\mathrm{GMR}^{ \pm}$ & $95 \% \mathrm{Cl}^{*}$ & $\begin{array}{l}\text { Adjusted } \\
\text { GMR }^{ \pm}\end{array}$ & $95 \% \mathrm{Cl}^{*}$ & $\mathbf{P}$ \\
\hline \multicolumn{6}{|l|}{ Sex } \\
\hline Men & 1 & & 1 & & 0.007 \\
\hline Women & 1.13 & $1.06-1.21$ & 1.12 & $1.03-1.22$ & \\
\hline \multicolumn{6}{|l|}{ Age group } \\
\hline $0-5$ years & 0.87 & 0.75-0.99 & 1.02 & $0.84-1.24$ & 0.526 \\
\hline $5-15$ years & 1.16 & $0.99-1.37$ & 1.14 & 0.93-1.39 & \\
\hline $15-25$ years & 1.00 & $0.89-1.23$ & 0.93 & $0.81-1.08$ & \\
\hline $25-35$ years & 1 & & 1 & & \\
\hline $35-45$ years & 1.00 & $0.92-1.08$ & 0.96 & $0.87-1.06$ & \\
\hline$\geq 45$ years & 1.00 & $0.90-1.10$ & 0.96 & 0.84-1.09 & \\
\hline \multicolumn{6}{|l|}{ Site of HIV test } \\
\hline QECH & 1 & & 1 & & \\
\hline $\begin{array}{l}\text { Facility other } \\
\text { than QECH }\end{array}$ & 1.65 & $1.54-1.77$ & 1.61 & $1.47-1.77$ & $<0.001$ \\
\hline Unknown & 1.82 & $1.64-2.02$ & 1.93 & $1.66-2.24$ & \\
\hline
\end{tabular}

\begin{tabular}{|c|c|c|c|c|c|}
\hline Stage 1 or 2 & 1 & & & & \\
\hline Stage 3 or 4 & 1.01 & 0.95-1.08 & & & \\
\hline \multicolumn{6}{|l|}{ 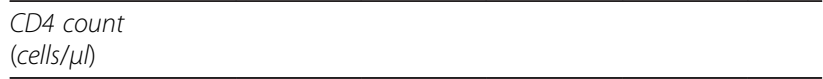 } \\
\hline$\geq 350$ & 1 & & 1 & & $<0.001$ \\
\hline $250-350$ & 0.87 & $0.70-1.11$ & 0.96 & $0.75-1.20$ & \\
\hline $50-250$ & 0.76 & $0.61-0.95$ & 0.77 & $0.62-0.98$ & \\
\hline$<50$ & 0.50 & $0.40-0.63$ & 0.53 & $0.42-0.68$ & \\
\hline \multicolumn{6}{|l|}{$\begin{array}{l}\text { Year of ART } \\
\text { initiation }\end{array}$} \\
\hline 2004 & 0.92 & $0.75-1.14$ & 0.79 & $0.52-1.21$ & 0.004 \\
\hline 2005 & 1 & & 1 & & \\
\hline 2006 & 0.72 & $0.60-0.87$ & 0.75 & $0.48-1.16$ & \\
\hline 2007 & 0.64 & $0.55-0.76$ & 0.71 & 0.50-1.03 & \\
\hline 2008 & 0.68 & $0.59-0.80$ & 0.72 & $0.51-1.02$ & \\
\hline 2009 & 0.69 & $0.59-0.80$ & 0.69 & $0.49-0.99$ & \\
\hline 2010 & 0.75 & $0.64-0.88$ & 0.85 & $0.60-1.21$ & \\
\hline 2011 & 0.54 & $0.47-0.63$ & 0.84 & $0.59-1.21$ & \\
\hline $\begin{array}{l}\text { Number of ART } \\
\text { initiators per year } \\
\text { (continuous) }\end{array}$ & 1.00 & $1.00-1.00$ & & & \\
\hline
\end{tabular}

${ }^{ \pm}$Bootstrapped estimates of geometric mean ratios, adjusted for sex, age group, site of HIV test, CD4 count strata and year of ART initiation.

Bias corrected accelerated $95 \%$ confidence intervals.

GMR Geometric mean ratio, $\mathrm{Cl}$ confidence interval, QECH Queen Elizabeth Central Hospital.

recommended in the Malawian National Programme and implemented at QECH, continues to meet its objective of providing rapid access to ART despite extremely limited resources.

In September 2011, new Malawian National ART guidelines were introduced promoting initiation of ART for HIV- infected individuals with a CD4 count of $<350$ cells/ $\mu l$, or in WHO stage 3 or 4, or who are pregnant or breastfeeding [11]. Given the long experience of providing ART with no appreciable increase in delay seen in this study, we anticipate that time to initiation will continue to shorten although with a greater number of potential patients meeting eligibility criteria, current levels of resourcing will need to be sustained or increased. This study found an overall median treatment delay of 35 days, although this varied cover time and was considerably shorter in more recent years. This compares similarly with other national programmes in the region: a recent systematic review found that the majority of ART initiators started treatment within one month [12], although two studies reported higher median delays of 2.4 months [13] and 6.6 months [14].

A key success to the sustainability of the Malawian national programme has been decentralisation of ART services from tertiary facilities to primary health care centres [15]. However, we found that patients who were diagnosed with HIV at a site outside of QECH and subsequently attended QECH for ART initiation were significantly more likely to experience delay. This may have been because, unlike patients who were diagnosed within QECH, they would have had to make repeated journeys to the hospital for ART eligibility assessments and treatment education classes [16]. Further, patients who were diagnosed at a primary care facility and opted to initiate ART at QECH may have had more complex clinical problems requiring specialist care that delayed ART initiation. Alternatively, they may have been reluctant to return to the primary health care centre for treatment because of anticipated stigma or previous bad experiences with providers [17]. Finally, individuals diagnosed with HIV at the tertiary hospital may have had more advanced immunosuppression, which mean that CD4 eligibility thresholds would be met earlier.

Women had longer delay to ART initiation than men, possibly reflecting their propensity to be diagnosed earlier in the course of their infection through routine HTC during antenatal care $[8,18]$. Men are known to initiate ART at a more advanced stage of illness and with lower CD4 counts than women [19] and have a higher risk of immediate post-ART initiation mortality $[20,21]$. In this study, we were not able to adjust for the effect of pregnancy (which is associated with diagnosis at an earlier stage of HIV infection [8]) at ART initiation to determine whether this could have explained women's longer delay. Nevertheless, given that more women currently access ART in sub-Saharan Africa [2], further studies, including qualitative research, are required to understand the gendered factors contributing to delay between HIV diagnosis and initiation of ART. 
Factors resulting in delay between HIV diagnosis and initiation of ART can include the complexity and timeconsuming nature of eligibility assessments (CD4 count measurement and WHO clinical staging) $[8,14,22]$, especially when these require substantial patient expenditure and repeat facility visits [23]. Moves towards introducing point-of-care CD4 count measurement [24] within HIV testing sites should allow same-day, same-clinic eligibility assessments reducing delays for men and women, while the universal ART eligibility of pregnant women infected with HIV in Malawi ("Option B+") [25] should result in more rapid initiation of treatment for pregnant women. We noted peaks in ART initiations in 2004 and 2005, after ART became freely available at the clinic through the national treatment programmes. There are two possible related reasons for this. Firstly, the large number of individuals who were awaiting treatment could have overwhelmed clinic capacity. However, we found that the number of clients initiating ART per year was not significantly associated with delay. Alternatively with treatment guidelines stipulating that only individuals with advanced immunosuppression (CD4 count $<200$ cells/ $\mu \mathrm{l}$ were eligible for ART during this time, overall HIV diagnosed individuals may have had to wait longer before they met ART eligibility criteria.

The majority of ART initiators in this study were adolescents and young adults. Adolescents were significantly more likely to initiate ART with advanced HIV infection than individuals in other age groups. This supports data from Zimbabwe showing that HIV-infected adolescents are a neglected group, with high rates of undiagnosed HIV [26], late presentation for care with high a prevalence of chronic complications $[27,28]$ and numerous socio-economic complications, including an extremely high rate of orphanhood of 73\% [28] and emotional and psychological difficulties. We were reassured to find that, on adjusted analysis, adolescents and young adults did not have a higher risk of ART treatment delay, and this may be due to the availability of teen groups and integrated family clinics at QECH supporting access to care. However, the advanced stage of HIV at which the majority of children and adolescents are diagnosed requires urgent intervention, perhaps by including HIV screening as part of regular infant health screening clinics.

There were limitations to this study. We only examined delay from most recent positive HIV test to initiation of ART and some individuals may have tested positive on a prior occasion. Nearly $40 \%$ of ART initiators did not have complete data recorded for either date of most recent HIV-positive test or ART initiation, meaning that treatment delay may have been under- or over-estimated. As this was a retrospective cohort study (although using prospectively collected data), we were unable to assess several unrecorded variables which may have potentially impacted upon delay. Finally, we did not give a time-delineated definition of "delay" and instead used a continuous dependent variable within our regression models. This avoids oversimplification of a complex construct and recognises that criteria for ART initiation have evolved over time. However, it means that we cannot give a definite proportion of patients who were "delayed". New Malawian National guidelines [11] introduced in September 2011 recommend that ART is initiated within seven days of confirmed infection (for those meeting eligibility criteria). Even in the year with the shortest mean delay to treatment initiation (2011), only $18 \%$ of ART initiators initiated treatment within 7 days of their most recent positive HIV test. It will be important to continue to measure ART delays with regards to this target.

\section{Conclusion}

In conclusion, this study reports on substantial improvements in ART treatment delay in the largest facility providing care in Malawi, despite rapid programmatic scale-up over eight years. Although these achievements are impressive in the context of an extremely resourcelimited setting, a considerable decrease in treatment delay is still required, especially where "test-and-treat" approaches to ART are being considered. The increased risk of ART treatment delay among women emphasises the need to ensure equity in access to care.

\section{Competing interests}

The authors declare that they have no competing interests.

\section{Authors' contributions}

DJS, PM, JVO: Designed the study. EMP: Collected the data. PM: Undertook statistical analysis. DJS, PM, BoH, JVO, DGL: Wrote the first draft of the manuscript. All authors reviewed and approved the final manuscript.

\section{Acknowledgements}

We acknowledge the patients and clinical staff at the ART clinic, Queen Elizabeth Central Hospital and members of staff at Baobab Health who assisted with writing of database queries.

\section{Funding}

PM was funded by the Wellcome Trust (grant number: WT089673) DJS was funded by the Wellcome Trust (grant number: 086757/Z/08/A). The authors confirm that these funding bodies had no role in the design, analysis, collection, interpretation or decision to publish.

\section{Author details}

${ }^{1}$ Malawi-Liverpool-Wellcome Trust and Liverpool School of Tropical Medicine, Chichiri 3, PO 30096, Blantyre, Malawi. ${ }^{2}$ Centre for Global Health and Infection, University of Liverpool, Liverpool, UK. ${ }^{3}$ College of Medicine, University of Malawi, Mahatma Ghandi Road, Blantyre, Malawi. ${ }^{4}$ Faculty of Infectious and Tropical Diseases, Department of Clinical Sciences, Keppel Street, London, UK. ${ }^{5}$ Clinical Group, Liverpool School of Tropical Medicine, Pembroke Place, Liverpool L3 5QA, UK.

Received: 26 November 2012 Accepted: 14 May 2013 Published: 21 May 2013

\section{References}

1. UNAIDS: World AIDS Day Report. Geneva, Switzerland: UNAIDS; 2011. 
2. World Health Organization: Global HIV/AIDS response. Epidemic update and health sector progress towards universal access. Progress report. Geneva, Switerland: World Health Organization; 2011

3. Lowrance DW, Makombe S, Harries AD, Shiraishi RW, Hochgesang M, Aberle-Grasse J, Libamba E, Schouten E, Ellerbrock T, Kamoto K: A public health approach to rapid scale-up of antiretroviral treatment in Malawi during 2004-2006. J Acquir Immune Defic Syndr 2008, 49(3):287-293.

4. World Health Organization: Antiretroviral therapy for HIV infection in adults and adolescents: recommendations for a public health approach. Geneva, Switerland: World Health Organization; 2010

5. Harries AD, Makombe SD, Libamba E, Schouten EJ: Why did the scale-up of hiv treatment work?: a case example from Malawi. J Acquir Immune Defic Syndr 2011, 57(Suppl 2):S64-67.

6. Ministry of Health: Quarterly HIV Programme Report 2011, Q2. Lilongwe, Malawi: Ministry of Health, Government of Malawi; 2011.

7. Rosen S, Fox MP: Retention in HIV care between testing and treatment in Sub-Saharan Africa: a systematic review. PLoS Med 2011, 8(7):e1001056.

8. Macpherson P, Lalloo DG, Choko AT, Mann GH, Squire SB, Mwale D, Manda E, Makombe SD, Desmond N, Heyderman R, et al: Suboptimal patterns of provider initiated HIV testing and counselling, antiretroviral therapy eligibility assessment and referral in primary health clinic attendees in Blantyre, Malawi. TM \& IH 2012, 17(4):507-517.

9. van Oosterhout JJ, Kumwenda JK, Hartung T, Mhango B, Zijlstra EE: Can the initial success of the Malawi ART scale-up programme be sustained? The example of Queen Elizabeth Central Hospital, Blantyre. AIDS Care 2007, 19(10):1241-1246.

10. Douglas GP, Gadabu OJ, Joukes S, Mumba S, McKay MV, Ben-Smith A, Jahn A, Schouten EJ, Landis Lewis Z, van Oosterhout JJ, et al: Using touchscreen electronic medical record systems to support and monitor national scale-up of antiretroviral therapy in Malawi. PLoS Med 2010, 7(8):e1000319.

11. Ministry of Health: Clinical Management of HIV in Children and Adults. Lilongwe, Malawi: Ministry of Health, Government of Malawi; 2011.

12. Kranzer K, Govindasamy D, Ford N, Johnston V, Lawn SD: Quantifying and addressing losses along the continuum of care for people living with HIV infection in sub-Saharan Africa: a systematic review. J Int AIDS SOC 2012, 15(2):17383.

13. Micek MA, Gimbel-Sherr K, Baptista AJ, Matediana E, Montoya P, Pfeiffer J, Melo A, Gimbel-Sherr S, Johnson W, Gloyd S: Loss to follow-up of adults in public HIV care systems in central Mozambique: identifying obstacles to treatment. J Acquir Immune Defic Syndr 2009, 52(3):397-405.

14. Bassett IV, Regan S, Chetty S, Giddy J, Uhler LM, Holst H, Ross D, Katz JN, Walensky RP, Freedberg KA, et al: Who starts antiretroviral therapy in Durban, South Africa?... not everyone who should. AIDS 2010, 24(Suppl 1):S37-44.

15. Bemelmans M, Van Den Akker T, Ford N, Philips M, Zachariah R, Harries A, Schouten E, Hermann K, Mwagomba B, Massaquoi M: Providing universal access to antiretroviral therapy in Thyolo, Malawi through task shifting and decentralization of HIV/AIDS care. Trop Med Int Health 2010.

16. Macpherson P, Corbett EL, Makombe SD, van Oosterhout JJ, Manda E, Choko AT, Thindwa D, Squire SB, Mann GH, Lalloo DG: Determinants and consequences of failure of linkage to antiretroviral therapy at primary care level in Blantyre, Malawi: a prospective cohort study. PLoS One 2012, 7(9):e44794.

17. Roura M, Busza J, Wringe A, Mbata D, Urassa M, Zaba B: Barriers to sustaining antiretroviral treatment in Kisesa, Tanzania: a follow-up study to understand attrition from the antiretroviral program. AIDS Patient Care STDS 2009, 23(3):203-210.

18. Druyts E, Dybul M, Kanters S, Nachega J, Birungi J, Ford N, Thorlund K, Negin J, Lester R, Yaya S, et al: Male sex and the risk of mortality among individuals enrolled in antiretroviral therapy programs in Africa: a systematic review and meta-analysis. AIDS 2013, 27(3):417-425.

19. Braitstein P, Boulle A, Nash D, Brinkhof MW, Dabis F, Laurent C, Schechter M, Tuboi SH, Sprinz E, Miotti P, et al: Gender and the use of antiretroviral treatment in resource-constrained settings: findings from a multicenter collaboration. J Wom Health (2002) 2008, 17(1):47-55.

20. Lawn SD, Harries AD, Anglaret X, Myer L, Wood R: Early mortality among adults accessing antiretroviral treatment programmes in sub-Saharan Africa. AIDS 2008, 22(15):1897-1908.

21. MacPherson P, Moshabela M, Martinson N, Pronyk P: Mortality and loss to follow-up among HAART initiators in rural South Africa. Trans $R$ Soc Trop Med Hyg 2009, 103(6):588-593.
22. Bassett IV, Wang B, Chetty S, Mazibuko M, Bearnot B, Giddy J, Lu Z, Losina E, Walensky RP, Freedberg KA: Loss to care and death before antiretroviral therapy in Durban, South Africa. J Acquir Immune Defic Syndr 2009, 51(2):135-139.

23. Zachariah R, Harries AD, Manzi M, Gomani P, Teck R, Phillips M, Firmenich P: Acceptance of anti-retroviral therapy among patients infected with HIV and tuberculosis in rural Malawi is low and associated with cost of transport. PLoS One 2006, 1:e121.

24. Jani IV, Sitoe NE, Alfai ER, Chongo PL, Quevedo Jl, Rocha BM, Lehe JD, Peter TF: Effect of point-of-care CD4 cell count tests on retention of patients and rates of antiretroviral therapy initiation in primary health clinics: an observational cohort study. Lancet 2011, 378(9802):1572-1579.

25. Schouten EJ, Jahn A, Midiani D, Makombe SD, Mnthambala A, Chirwa Z, Harries AD, van Oosterhout JJ, Meguid T, Ben-Smith A, et al: Prevention of mother-to-child transmission of HIV and the health-related Millennium Development Goals: time for a public health approach. Lancet 2011 378(9787):282-284

26. Ferrand RA, Munaiwa L, Matsekete J, Bandason T, Nathoo K, Ndhlovu CE, Munyati S, Cowan FM, Gibb DM, Corbett EL: Undiagnosed HIV infection among adolescents seeking primary health care in Zimbabwe. Clin Infect Dis 2010, 51(7):844-851.

27. Desai SR, Copley SJ, Barker RD, Elston CM, Miller RF, Wells AU, Munyati S, Nathoo K, Corbett EL, Ferrand RA: Chest radiography patterns in 75 adolescents with vertically-acquired human immunodeficiency virus (HIV) infection. Clin Radiol 2011, 66(3):257-263.

28. Ferrand RA, Bandason T, Musvaire P, Larke N, Nathoo K, Mujuru H, Ndhlovu CE, Munyati S, Cowan FM, Gibb DM, et al: Causes of acute hospitalization in adolescence: burden and spectrum of HIV-related morbidity in a country with an early-onset and severe HIV epidemic: a prospective survey. PLoS Med 2010, 7(2):e1000178.

doi:10.1186/1471-2458-13-490

Cite this article as: Sloan et al:: Evidence of improving antiretroviral therapy treatment delays: an analysis of eight years of programmatic outcomes in Blantyre, Malawi. BMC Public Health 2013 13:490.

\section{Submit your next manuscript to BioMed Central and take full advantage of:}

- Convenient online submission

- Thorough peer review

- No space constraints or color figure charges

- Immediate publication on acceptance

- Inclusion in PubMed, CAS, Scopus and Google Scholar

- Research which is freely available for redistribution 